\title{
Reply to "Better Safe than Sorry: Interventional Radiology Should Be Prepared for the Coronavirus Disease 2019 Pandemic"
}

\author{
Pawan K. Garg ${ }^{1, \odot}$ Sarbesh Tiwari ${ }^{1, \odot}$ Binit Sureka \\ ${ }^{1}$ Department of Diagnostic and Interventional Radiology, All India \\ Institute of Medical Sciences, Jodhpur, Rajasthan, India
}

J Clin Interv Radiol ISVIR:2021;5:66-67

We read with interest the review article Better Safe than Sorry: Interventional Radiology Should Be Prepared for the Coronavirus Disease 2019 Pandemic by Babu et al published in your esteemed journal in April 2020. ${ }^{1}$ The authors have beautifully addressed the important tips about interventional radiology (IR) practice in the setting of coronavirus disease 2019 (COVID-19) pandemic. We want to add some points with regard to the IR practice in COVID-19.

As radiologists, we all know about the principle of time, distance, and shielding for radiation protection; the same can also be applied to the COVID-19 situation.

\section{Time}

Various measures need to be taken to reduce the total duration of the procedure. All hardware should be ready on the table before the patient enters the angiography suite. The procedure should be performed by the most trained person in the team and assisted by trained staff. The use of vascular closure device rather than manual compression should be considered. The patient's stay inside the angiography suite pre- and postprocedure should be minimized.

\section{Shielding}

This is the most important aspect that includes personal protection equipment (PPE) for all health care workers (HCWs). In addition, all surfaces that are likely to come in contact with the patient, such as tabletop, detector, and radiation curtains, should be covered by a disposable, water impervious plastic cover. It is to reiterate that the proper use of the radiation curtains and lead barrier adds to the protection of the operator from aerosols.

published online

June 8,2020
DOI https://doi.org/

10.1055/s-0040-1713696

ISSN 2457-0214.
Address for correspondence Sarbesh Tiwari, DM, Department of Diagnostic and Interventional Radiology, All India Institute of Medical Sciences, Basni Industrial Area Phase 2, Jodhpur, Rajasthan 342005, India (e-mail: sarbesh1984@gmail.com).

\section{Distance}

If possible, the primary operator should avoid proximity to the patient's face while performing the procedure. For example, the femoral approach should be used rather than the jugular approach for emergency inferior vena cava filter placement. Social distancing should be maintained by the HCWs inside the angiography suite without compromising the patient's care.

In addition, the following points should also be considered by the IR team:

- Segregation of HCWs: If possible, the IR team including technical, nursing, and support staff should be divided into two groups. These two groups should work by weekly rotation without coming in contact with each other.

- Avoiding central air conditioning: The central air conditioner (AC) should be switched off before the patient enters the angiography suite. If available, it is better to use stand-alone closed AC systems in angiography rooms. Cleaning of AC filters is recommended after any procedure performed on COVID-19 positive or suspected patients.

- Universal usage of mask: All patients regardless of the presence or absence of respiratory symptoms should be wearing the triple-layer surgical mask before entering the angiography room. The same rule applies to all the digital subtraction angiography (DSA) and support staff.

- Universal safety precaution: All emergency cases such as stroke, brain aneurysm coiling, and acute bleeders, should be considered as positive and handled with all recommended precautions. It is pertinent to add that there is recent literature describing acute ischemic stroke as being one of the presentations of COVID-19 infection. ${ }^{2}$

Finally, we second the statement "better safe than sorry" in this hour of a COVID-19 pandemic. (c) 2020. Indian Society of Vascular and Interventional Radiology.

This is an open access article published by Thieme under the terms of the Creative Commons Attribution-NonDerivative-NonCommercial-License, permitting copying and reproduction so long as the original work is given appropriate credit. Contents may not be used for commercial purposes, or adapted, remixed, transformed or built upon. (https://creativecommons.org/licenses/by-nc-nd/4.0/).

Thieme Medical and Scientific Publishers Pvt. Ltd. A-12, 2nd Floor, Sector 2, Noida-201301 UP, India 


\section{Funding}

None.

\section{Presentation at a Meeting}

None.

\section{Conflict of Interest}

None.

\section{Reference}

1 Babu AAS, Padmanabhan A, Khera PS, Sonwalkar H. Better safe than sorry: interventional radiology should be prepared for the coronavirus disease 2019 pandemic. J Clin Interv Radiol ISVIR 2020;4:38-41

2 Avula A, Nalleballe K, Narula N, et al. COVID-19 presenting as stroke. Brain Behav Immun 2020 (e-pub ahead of print). Doi:10.1016/j.bbi.2020.04.077 